\title{
Mitigation of Drought Stress Damage by Exogenous Application of a Non-Protein Amino Acid $\gamma$ - Aminobutyric Acid on Perennial Ryegrass
}

\author{
Sanalkumar Krishnan, Kevin Laskowski, Vijaya Shukla, and Emily B. Merewitz ${ }^{\mathbf{1}}$ \\ Department of Plant, Soil, and Microbial Sciences, Michigan State University, 1066 Bogue Street, \\ East Lansing, MI 48824
}

\begin{abstract}
Additional Index words. Lolium perenne, GABA, water stress, turfgrass, chemical priming, drought tolerance
Abstract. Perennial ryegrass (Lolium perenne) is an important forage and turfgrass species that is sensitive to drought stress. The objective of this study was to investigate whether gamma aminobutyric acid (GABA) may play a role in promoting drought tolerance in grass species. GABA was exogenously applied as a foliar spray at the rate of 50 or $70 \mathrm{~mm}$ to perennial ryegrass 'CSI' under well-watered or drought-stressed conditions in a controlledenvironment growth chamber. The effect of GABA on the growth physiology, drought stress response, antioxidant activity, and lipid peroxidation of perennial ryegrass exposed to drought stress was measured. GABA-treated perennial ryegrass exposed to drought stress had higher relative water content (RWC), turf quality, and peroxidase activity and lower wilt rating, canopy temperature depression, electrolyte leakage, and lipid peroxidation compared with untreated plants. GABA application had no significant effect on the activity of superoxide dismutase and catalase under well-watered and drought conditions. GABA application at $50 \mathrm{~mm}$ was found to be more effective in alleviating drought stress damage in perennial ryegrass. The results from this study suggest that GABA mitigated drought stress damage in perennial ryegrass by maintaining higher RWC and membrane stability.
\end{abstract}

Perennial ryegrass is a widely used C3 turfgrass and forage species in both cool- and warm-season areas (Turgeon, 2005). Drought is one of the major abiotic stress factors affecting perennial ryegrass growth and functionality. Drought stress retards turfgrass growth and causes deterioration of turf quality (TQ) by affecting various physiological and biochemical factors (McCann and Huang, 2007). Drought stress in perennial turfgrass species causes stress damage such as loss of cellular water content and chlorophyll and increased oxidative stress leading to leaf and root senescence (DaCosta and Huang, 2006). When compared with the more drought-tolerant grass species kentucky bluegrass (Poa pratensis), perennial ryegrass exhibits lower relative water content, osmotic adjustment, and cell wall extensibility under drought stress and a lower rate of recovery from drought stress (Chai et al., 2010). Evidence such as this indicates perennial ryegrass is a relatively drought-sensitive grass species. Therefore, evaluating the function of plant metabolites such as GABA that may promote the drought tolerance of perennial ryegrass and other turfgrasses is needed.

GABA is a four-carbon non-protein amino acid conserved from prokaryotes to eukaryotes (Bown and Shelp, 1997; Shelp et al., 2012). In animals, GABA is well known to function as a neurotransmitter in the central nervous system activated through GABA receptors (Bouche and Fromm, 2004). Less is known about the role of GABA in plant species, particularly regarding the function of GABA during abiotic stresses in grasses. Several studies reported that GABA often rapidly accumulates in plants in response to abiotic and biotic stresses including drought, salt, wounding, hypoxia, heat shock, and pathogen infection (Fait et al., 2005; Kinnersley and Turano, 2000; Shelp et al., 1999). However, whether this accumulation is for stress protection or the result of cellular damage is not yet

Received for publication 24 May 2013. Accepted for publication 17 June 2013. ${ }^{1}$ Corresponding author. E-mail: merewitz@msu.edu. fully understood. GABA is synthesized from glutamate through glutamate decarboxylase and then converted to succinic semialdehyde (SSA) and succinate before entering the tricarboxylic acid cycle (Shelp et al., 2012). Recent developments in arabidopsis (Arabidopsis thaliana) functional genomics suggest that GABA acts as a signal molecule acting in concert with phytohormones such as abscisic acid and ethylene (Lancien and Roberts, 2006; Renault et al., 2011).

Metabolites such as GABA and other sugars, sugar alcohols, amino acids, and amines accumulate under drought stress in several plant species (Seki et al., 2007; Taji et al., 2002). These metabolites can function as osmolytes, antioxidants, or reactive oxygen scavengers that help plants to tolerate stresses. Metabolite evaluation of transgenic creeping bentgrass (Agrostis stolonifera) plants with elevated cytokinin (CK) content under drought stress revealed that GABA accumulated to a much greater extent in the more drought-tolerant plants compared with the sensitive plants (Merewitz et al., 2012). This is consistent with studies of barley (Hordeum vulgare) that showed higher expression of GABA receptor genes in drought-tolerant cultivars than in sensitive ones (Guo et al., 2009). Whether GABA accumulates for stress protection or as a result of stress damage in grass species is not known. There is some evidence indicating that exogenous GABA may influence the antioxidant responses of plants. Soaking peach (Prunus persica) fruit in GABA enhanced the antioxidant activity in response to chilling stress of the fruit (Yang et al., 2011). In grasses, drought stress generates active oxygen species, which causes oxidative damage to lipids, nucleic acids, and proteins (Smirnoff, 1993). Therefore, whether GABA may influence the antioxidant response and whether it may impact turfgrass physiological responses to abiotic stress deserves investigation.

The development of an efficient antioxidant defense system is crucial for grass survival under drought stress. In various perennial ryegrass accessions differing in drought susceptibility, 
Liu and Jiang (2010) found by differential genetic analysis that the antioxidant enzyme glutathione peroxidase and other antioxidants play a major role in conferring drought tolerance in perennial ryegrass. Identification of chemical compounds such as GABA with the potential to enhance drought tolerance, particularly those that act to enhance antioxidant responses in perennial ryegrass, would be valuable for future use in product development and genetic modification (Karnok, 2000; Zhang and Schmidt, 2000). The objectives of the study were to evaluate the effects of exogenous applications of various rates of GABA on the response of perennial ryegrass to drought stress conditions on a physiological basis and to evaluate the effects on antioxidant responses.

\section{Materials and Methods}

Plant material and growth conditions. Uniform sod pieces ( $10.16 \mathrm{~cm}$ diameter) of perennial ryegrass 'CSI' were taken from the Hancock Turfgrass Research Center in East Lansing, MI. The sod pieces were established in a greenhouse maintained at average day/night temperatures of $23 / 16^{\circ} \mathrm{C}$ and an average $12-\mathrm{h}$ photoperiod at $400 \mu \mathrm{mol} \cdot \mathrm{m}^{-2} \cdot \mathrm{s}^{-1}$ photosynthetically active radiation. The pots in which the plants were grown were $40-\mathrm{cm}$ polyvinyl chloride tubes filled with a loamy Typic Hapludult soil and pure sand uniformly mixed at a ratio of one soil:two sand $(\mathrm{v} / \mathrm{v})$. Plants were fertilized with halfstrength Hoagland solution and trimmed equally on a weekly basis. Plants were then transferred to an environmental growth chamber. The growth chamber conditions included a light level of $260 \mu \mathrm{mol} \cdot \mathrm{m}^{-2} \cdot \mathrm{s}^{-1}$ with a $14-\mathrm{h}$ photoperiod, a red:far red ratio of $4.4,21.5^{\circ} \mathrm{C}$ ambient temperature, and $65 \%$ relative humidity. Plants were maintained in the growth chamber for $7 \mathrm{~d}$ to acclimate to chamber conditions before imposing drought treatments.

Treatments and eXPerimental Design. The plants were exposed to six treatments: 1) well-watered control, irrigated every $2 \mathrm{~d}$ to maintain soil volumetric water content (SVC) at $25 \%(\mathrm{v} / \mathrm{v}) ; 2)$ well-watered plants treated with GABA $50 \mathrm{~mm}$ ( $99 \%$ or greater; Sigma Aldrich, St. Louis, MO) applied as a foliar spray; 3) well-watered plants treated with $70 \mathrm{~mm}$ GABA; 4) drought stress, irrigation completely withheld; 5) droughtstressed plants treated with $50 \mathrm{~mm}$ GABA; and 6) droughtstressed plants treated with $70 \mathrm{~mm}$ GABA. The plants were given a single application of GABA as a foliar spray $1 \mathrm{~d}$ before the irrigation was withheld. The concentrations of 50 and $70 \mathrm{~mm}$ GABA were selected based on other studies investigating GABA exogenously (Barbosa et al., 2010). Well-watered plants were watered before and $1 \mathrm{~d}$ after GABA treatment as to not wash off the spray treatment. The treatments were arranged in a completely randomized design with a total of 18 experimental units. All treatments were replicated three times and measurements were taken at multiple sampling dates during the treatment period. Each GABA-treated pot was sprayed with a volume of $5 \mathrm{~mL}$ GABA at the concentrations mentioned. All control pots were treated with the same volume of water equal to that applied on the GABA treatment pots. SVC was measured using a soil moisture meter (TDR 100; Spectrum Technologies, Plainfield, IL) in a 0 - to 20 -cm-deep soil layer of each pot by inserting the $20-\mathrm{cm}$-long rod vertically in the soil.

Physiological measurements. The measurements were taken on 1,7,9, and $14 \mathrm{~d}$ after the initiation of water treatments. TQ was rated visually based on color, density, and uniformity of the grass using a scale of 1 to $9[9=$ fully turgid, dense green canopy, 1 = completely dead plants (Beard, 2001)].

Leaf RWC was determined on each sampling day using 10 to 12 fully expanded leaves per pot using the method described by Barrs and Weatherley (1962). Leaves were harvested from plants and weighed immediately to determine the fresh weight (FW). The leaves were placed in covered petri dishes filled with water and kept at $4{ }^{\circ} \mathrm{C}$ overnight to reach full hydration. Leaf samples were blotted dry and weighed immediately to determine the turgid weight (TW). Leaf tissues were dried in an oven at $80{ }^{\circ} \mathrm{C}$ for $72 \mathrm{~h}$ and weighed to determine the dry weight (DW). Leaf RWC was calculated as $(\mathrm{FW}-\mathrm{TW}) /(\mathrm{TW}-\mathrm{DW}) \times 100$. The effect of drought stress on plants was visually evaluated by rating the leaf wilt. The wilt was rated on a 1 to 9 scale with 1 being fully turgid leaves with dark green color and 9 being fully wilted and dried leaves.

Canopy temperature depression (CTD) was calculated for estimating the effect of drought on leaf temperature using the formula (ambient temperature - leaf temperature) using an IR Crop Temperature Meter (Spectrum Technologies) held at a $45^{\circ}$ angle at a constant distance $(\approx 0.6 \mathrm{~m})$ from the turf canopy for each plant. Ambient temperature of the growth chamber was recorded with a separate thermometer located within the chamber during each measurement period.

Cell membrane stability of leaves was estimated by measuring the leaf electrolyte leakage (EL). Approximately 10 leaves were taken from each plant and washed with deionized water for three times and immersed in 25 to $30 \mathrm{~mL}$ of deionized water and placed in a shaker for $24 \mathrm{~h}$. The conductivity of the water containing the living tissue was measured as initial conductivity $(\mathrm{Ci})$. The leaf tissues were killed by boiling for $20 \mathrm{~min}$ and then placed in a shaker for $24 \mathrm{~h}$. The conductivity of the water containing the dead tissues was measured as the maximum conductance $\left(C_{\max }\right)$. The percentage EL was calculated as $C_{\mathrm{i}} / C_{\max }$ (Blum and Ebercon, 1981).

For determination of antioxidant activity, $250 \mathrm{mg}$ of fresh leaf tissue was ground to a fine powder using a mortar and pestle and extracted using $4 \mathrm{~mL}$ of extraction buffer [ $50 \mathrm{~mm}$ potassium phosphate buffer ( $\mathrm{pH} 7.0$ ), and $1 \%$ polyvinylpyrrolidone]. The extractions were centrifuged at $15,000 \mathrm{~g}_{\mathrm{n}}$ for $30 \mathrm{~min}$ at $4{ }^{\circ} \mathrm{C}$ and supernatant was collected for subsequent enzyme assay and quantification. Ascorbate peroxidase (APX) activity was measured based on the oxidation of ascorbate as described by Nakano and Assada (1981) with modifications. The reaction solution $(3 \mathrm{~mL})$ contained $100 \mathrm{~mm}$ sodium acetate $(\mathrm{pH} 5.8)$, $0.003 \mathrm{~mm}$ ethylenediaminetetraacetic acid, $10 \mathrm{~mm}$ ascorbate, and $100 \mu \mathrm{L}$ leaf extract. The absorbance changes at $290 \mathrm{~nm}$ were measured every $10 \mathrm{~s}$ for $60 \mathrm{~s}$ using a spectrophotometer (Genesys 10S; Thermo Scientific, Madison, WI). The absorbance change of $0.01 / \mathrm{min}$ was taken as one unit of APX activity. The peroxidase (POD) activity was measured by monitoring the increase in absorbency at $460 \mathrm{~nm}$ every $10 \mathrm{~s}$ for $60 \mathrm{~s}$ as guaiacol was oxidized according to the method of Chance and Maehly (1955). The POD reaction solution $(3 \mathrm{~mL})$ contained $0.1 \mathrm{M}$ sodium acetate buffer ( $\mathrm{pH} 5.0$ ), $0.25 \%$ guaiacol (resolved in $50 \%$ ethanol), $0.75 \% \mathrm{H}_{2} \mathrm{O}_{2}$, and $100 \mu \mathrm{L}$ of leaf extract. Catalase (CAT) activity was measured by the rate of decomposition of $\mathrm{H}_{2} \mathrm{O}_{2}$ at $240 \mathrm{~nm}$ in $3 \mathrm{~mL}$ of reaction mixture consisting of $50 \mathrm{~mm}$ sodium phosphate buffer and $45 \mathrm{~mm}_{2} \mathrm{O}_{2}$ (Chance and Maehly, 1955). Superoxide dismutase (SOD) activity was measured by its ability to inhibit p-nitro-blue tetrazolium chloride reduction at $560 \mathrm{~nm}$ (Giannopolitis and Ries, 1977). 
Lipid peroxidation level was determined based on malondialdehyde (MDA) content using the method of Dhindsa et al. (1981) with modifications. A 1.0-mL enzyme solution was added to $2 \mathrm{~mL}$ of reaction solution containing $20 \%(\mathrm{v} / \mathrm{v})$ trichloroacetic acid and $0.5 \%(\mathrm{v} / \mathrm{v})$ thiobarbituric acid. The solution was heated in a water bath at $95^{\circ} \mathrm{C}$ for $30 \mathrm{~min}$, quickly cooled on ice, and centrifuged at $10,000 \mathrm{~g}_{\mathrm{n}}$ for $30 \mathrm{~min}$. The absorbance readings were taken at 532 and $600 \mathrm{~nm}$. The nonspecific absorbance at $600 \mathrm{~nm}$ was subtracted from absorbance at $532 \mathrm{~nm}$ and MDA content was calculated using the adjusted absorbance and extinction coefficient of $155 \mathrm{~mm}^{-1} \cdot \mathrm{cm}^{-1}$ (Heath and Packer, 1968).

Statistical AnAlysis. Analysis of variance was based on the general linear model procedure of SAS (Version 9.1; SAS Institute, Cary, NC). Effects of the chemical treatment were analyzed by comparing with controls at the given measurement time. The Fisher's protected least significant difference (LSD) test at the $0.05 P$ level was used to detect the difference between treatment means. LSD bars were presented in the figures where a significant chemical effect was observed.

\section{Results}

The SVC averaged $\approx 24 \%$ across well-watered plants treated with 0,50 , or $70 \mathrm{~mm}$ GABA on all sampling dates (Fig. 1). SVC declined to $5.9 \%$ and $2 \%$ at 7 and $14 \mathrm{~d}$ in drought-treated pots. The rate of soil water depletion was not significantly different among the GABA-treated and untreated plants under drought treatment. RWC of well-watered plants was maintained at $\approx 90 \%$ for the entire duration of the study period (Fig. 2). The RWC declined in the drought stress plants and reached 29\% after $14 \mathrm{~d}$. A significant difference in RWC was observed between the GABA-treated and non-treated plants under drought stress. RWC was $14.2 \%, 42 \%$, and $27.5 \%$ higher in drought-stressed plants treated with $50 \mathrm{~mm}$ GABA than in nontreated plants at 7, 9, and $14 \mathrm{~d}$, respectively.

Turf quality declined in drought-stressed plants compared with well-watered control plants (Fig. 3). GABA at the rate of $50 \mathrm{~mm}$ sprayed on well-watered plants showed better TQ (8.7, 8.7, and 8.3) than watered controls (7.3, 7.3, and 7.0) at 7,9, and $14 \mathrm{~d}$ of treatment, respectively. GABA treated at the rate of $50 \mathrm{~mm}$ applied on drought-stressed perennial ryegrass plants maintained higher TQ $(7.3,6.3$, and 5.7) than non-treated plants $(5.7,4.3$, and 4.0$)$ at 7,9 , and $14 \mathrm{~d}$ of treatment, respectively. Drought-stressed plants sprayed with GABA at the rate of $70 \mathrm{~mm}$ maintained higher quality (6.3 and 5.3) than drought control plants (4.3 and 4.0) at 9 and $14 \mathrm{~d}$ of treatment, respectively. Leaf wilt was significantly lower in GABA-treated plants under drought than untreated plants (Fig. 4). GABA applied at the rate of $50 \mathrm{~mm}(2.0,3.0$, and 5.3) and $70 \mathrm{~mm}(2.7,4.3$, and 5.7) showed less wilt than control plants $(4.6,6.0$, and 7.0$)$ under drought stress.

The well-watered perennial ryegrass showed higher CTD (lower canopy temperature) than drought-stressed plants (Fig. 5). At 7 and $9 \mathrm{~d}$ of drought treatment, CTD of plants treated with $50 \mathrm{~mm} \mathrm{GABA}$ were higher $\left(2.2\right.$ and $\left.0.57^{\circ} \mathrm{C}\right)$ than untreated plants $\left(-0.23\right.$ and $\left.-2.47^{\circ} \mathrm{C}\right)$, respectively. The CTD was higher in plants treated with $70 \mathrm{~mm}$ GABA $(2.4,-0.5$, and $\left.-1.47^{\circ} \mathrm{C}\right)$ than control plants $\left(-0.23,-2.47\right.$, and $\left.-4.23{ }^{\circ} \mathrm{C}\right)$ at 7,9 , and $14 \mathrm{~d}$ of drought stress, respectively. The levels of EL increased significantly in drought-stressed plants compared with watered plants (Fig. 6). A reduction of $20.7 \%$ in EL was observed in drought-stressed plants treated with $70 \mathrm{~mm}$ GABA than drought alone at $9 \mathrm{~d}$ of treatment.

Drought stress significantly increased lipid peroxidation relative to well-watered control plants (Fig. 7). MDA content was $19.7 \%$ and $25.6 \%$ lower in plants applied with $50 \mathrm{~mm}$ GABA compared with untreated ones at 9 and $14 \mathrm{~d}$ of drought,

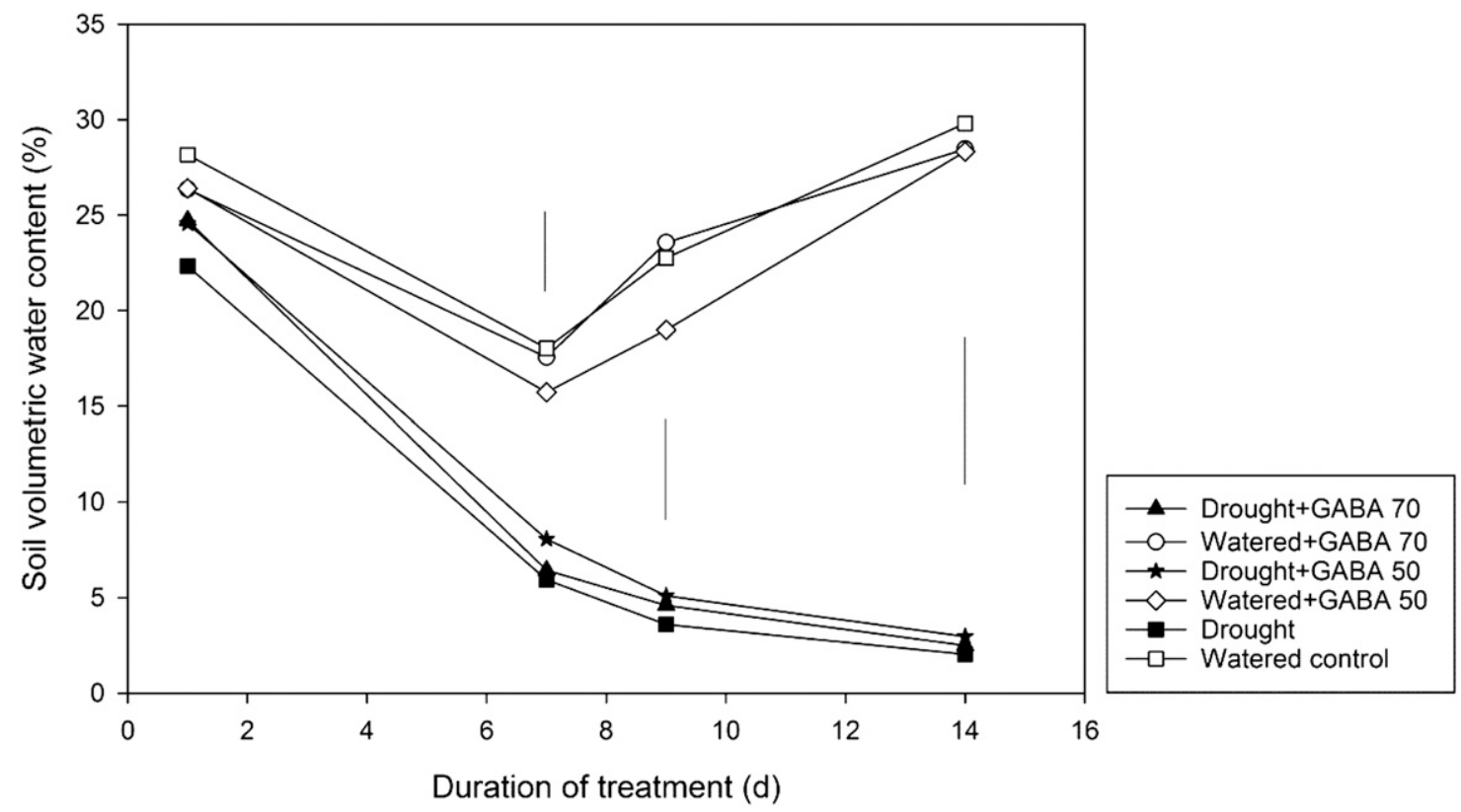

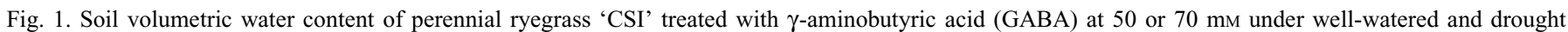
conditions. Vertical least significant difference (LSD) bars represent least significant difference values $(P \leq 0.05)$ for treatment comparison at a given day of treatment. 


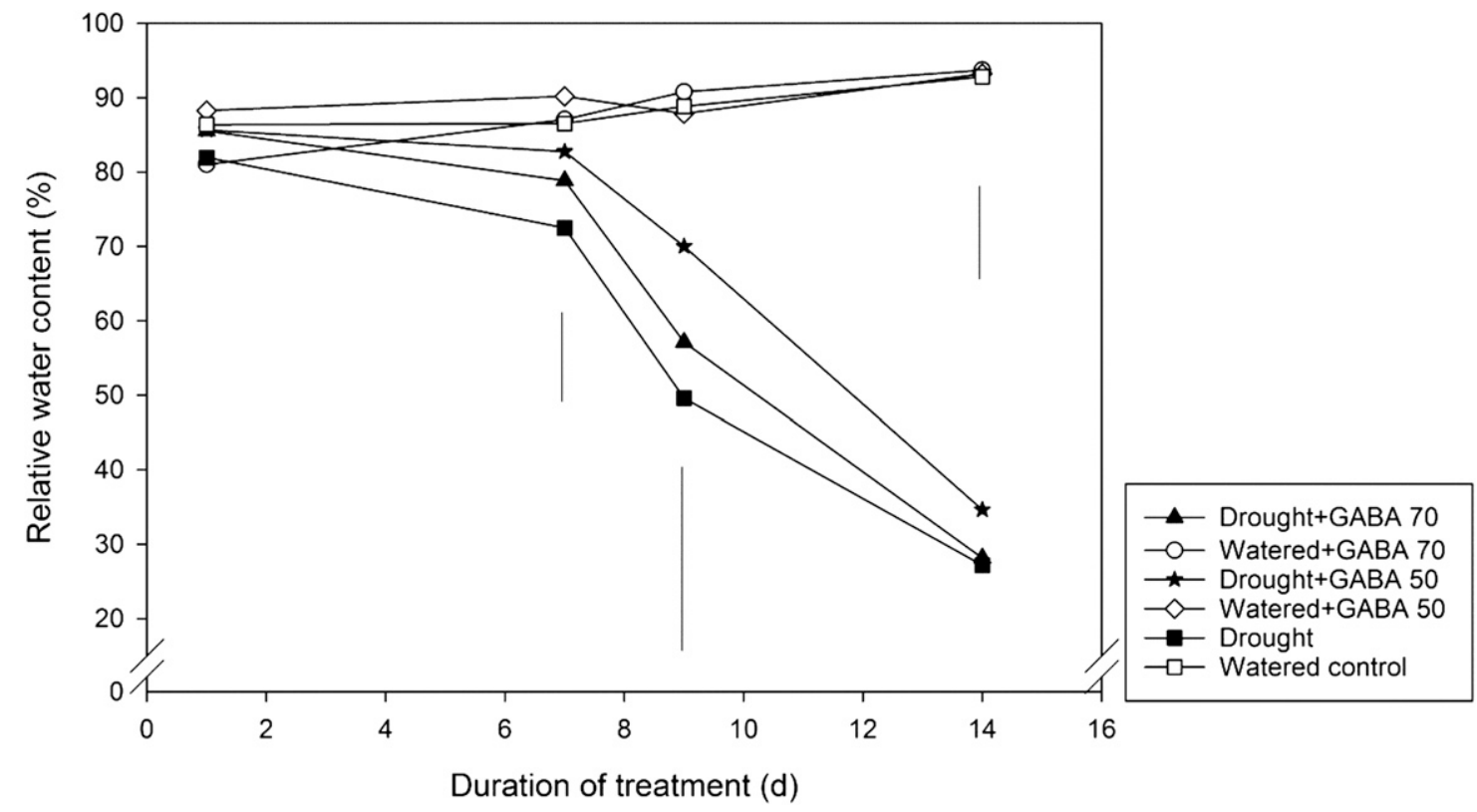

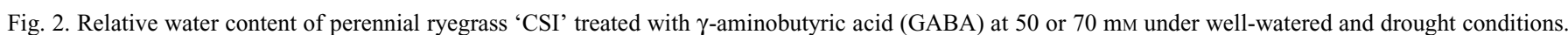
Vertical least significant difference (LSD) bars represent least significant difference values $(P \leq 0.05)$ for treatment comparison at a given day of treatment.

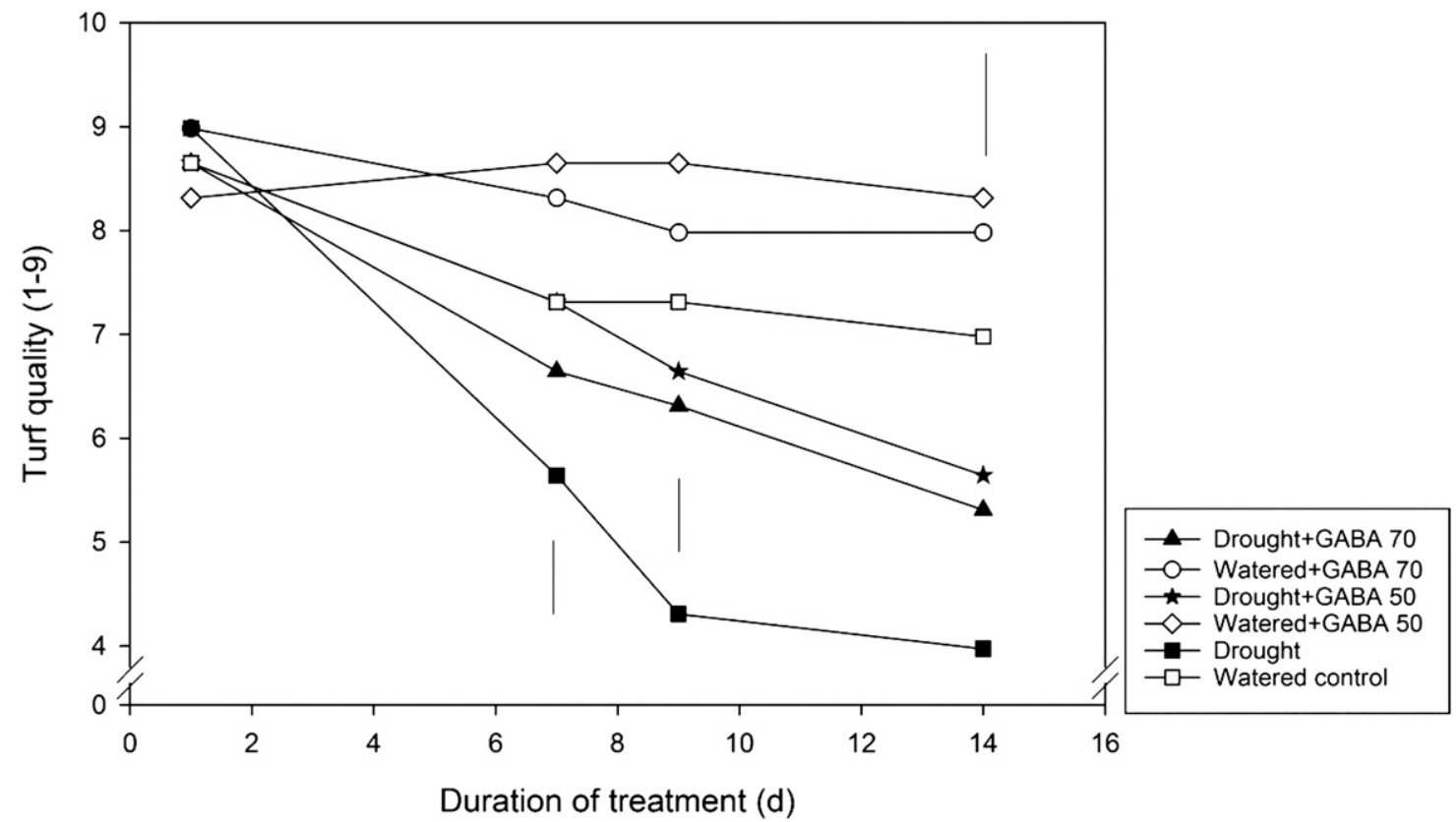

Fig. 3. Turf quality ( $9=$ healthy, $1=$ necrotic) of perennial ryegrass ' $\mathrm{CSI}$ ' treated with $\gamma$-aminobutyric acid (GABA) at 50 or 70 mu under well-watered and drought conditions. Vertical least significant difference (LSD) bars represent least significant difference values $(P \leq 0.05)$ for treatment comparison at a given day of treatment.

respectively. GABA applied at $70 \mathrm{~mm}$ under drought had $19.8 \%$ lower MDA content compared with untreated plants at $14 \mathrm{~d}$ of drought. The antioxidant activity of SOD, CAT, APX, and POD were measured in both treatment and control plants. Activities of SOD and CAT did not differ significantly in GABA-treated perennial ryegrass compared with control (data not shown). The APX activity was lower in drought-stressed plants compared with well-watered plants at $14 \mathrm{~d}$ of treatment (Fig. 8A). A 28\% reduction in APX activity is seen in drought-stressed plants treated with $50 \mathrm{~mm}$ GABA at $7 \mathrm{~d}$ of treatment. The activity of
POD was lower in drought-stressed plants than well-watered plants (Fig. 8B). The application of GABA ( $50 \mathrm{~mm})$ resulted in a 55\% higher POD activity in drought-stressed plants than nontreated plants at $14 \mathrm{~d}$ of treatment.

\section{Discussion}

The decline in SVC indicated that the drought treatment imposed severe water stress on plants. SVC in a $20-\mathrm{cm}$ soil depth declined to $\approx 2 \%$ after $14 \mathrm{~d}$ of drought treatment. Our 


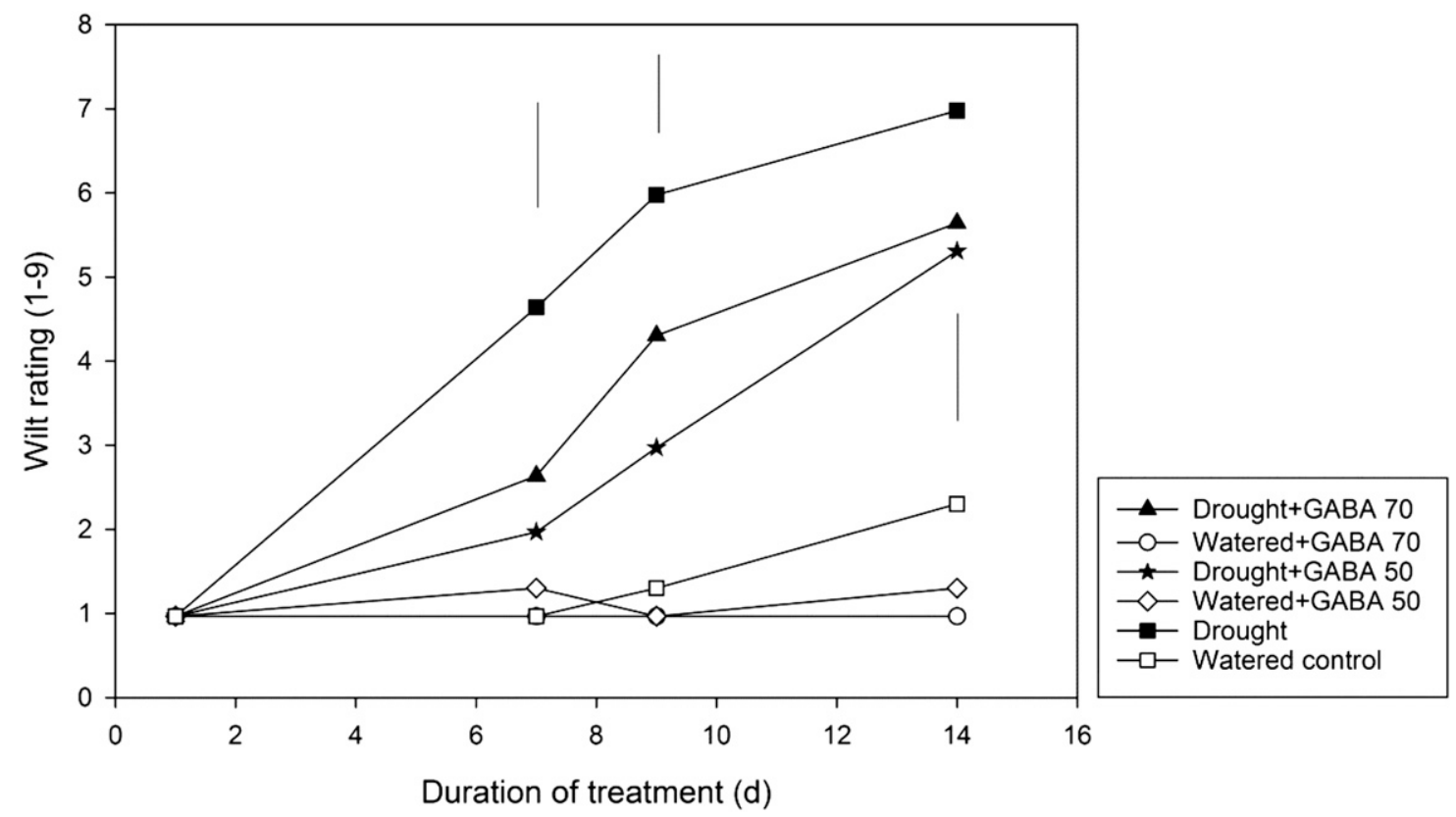

Fig. 4. Wilt rating $(9=$ necrotic, $1=$ turgid $)$ of perennial ryegrass 'CSI' treated with $\gamma$-aminobutyric acid (GABA) at 50 or 70 mM under well-watered and drought conditions. Vertical least significant difference (LSD) bars represent least significant difference values $(P \leq 0.05)$ for treatment comparison at a given day of treatment.

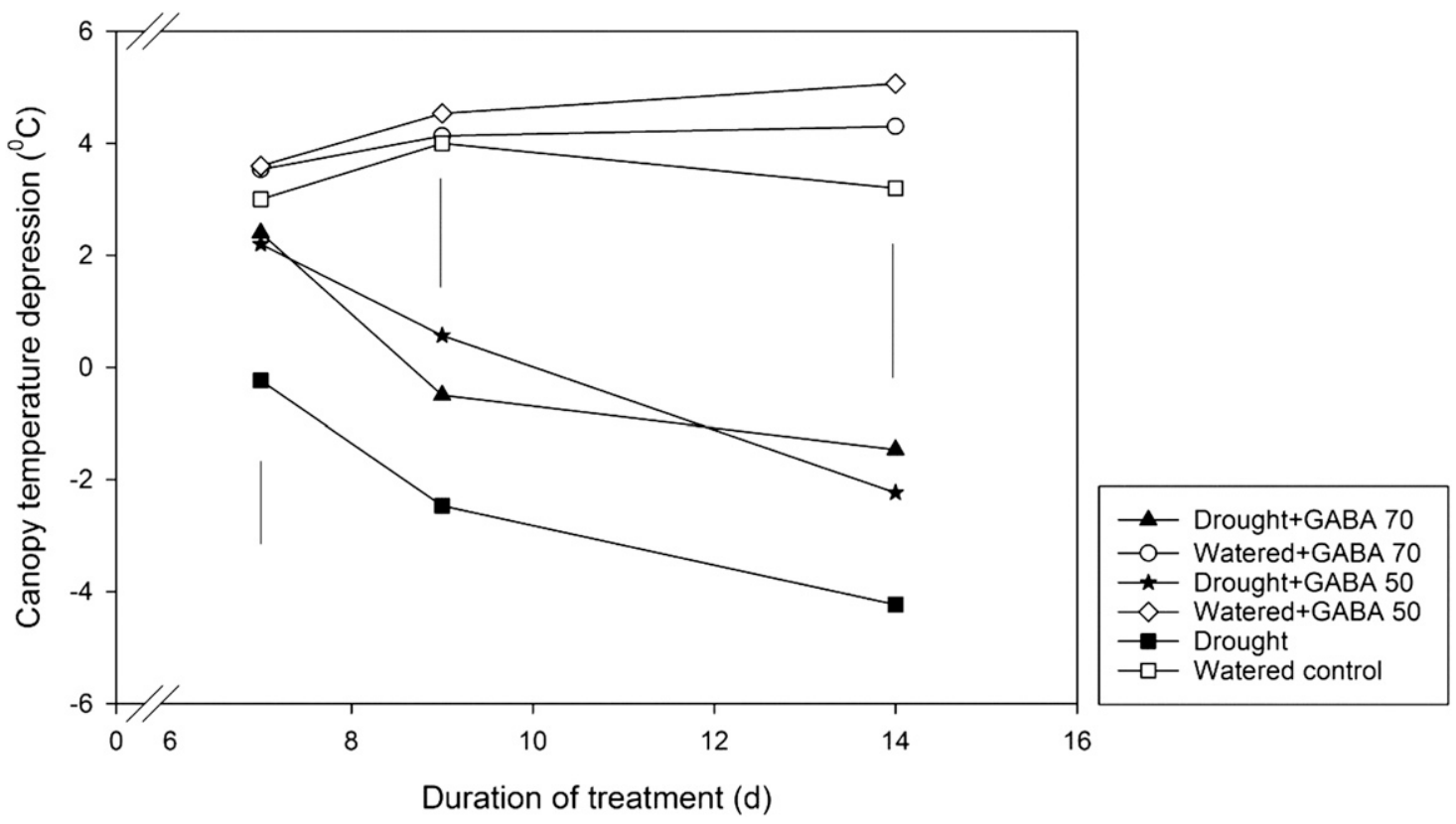

Fig. 5. Canopy temperature depression of perennial ryegrass 'CSI' treated with $\gamma$-aminobutyric acid (GABA) at 50 or 70 mM under well-watered and drought conditions. Vertical least significant difference (LSD) bars represent least significant difference values $(P \leq 0.05)$ for treatment comparison at a given day of treatment.

results demonstrate that GABA- $(50 \mathrm{~mm})$ treated perennial ryegrass maintained significantly higher RWC under drought stress than non-treated plants. RWC in leaves is a measure of internal water status during drought stress (Matin et al., 1989). The results suggest that GABA-treated perennial ryegrass plants were better able to maintain water under drought stress. The function of GABA as a compatible osmolyte under osmotic stress has been proposed by Shelp et al. (1999). Osmolyte accumulation in plant cells results in maintenance of cell turgor pressure and also protects cell membranes, protein, and metabolic machinery from cell dehydration (Hare et al., 1998; Ingram and Bartels, 1996; Rathinasabapathi, 2000). Two recent studies demonstrated that GABA was differentially accumulated in hybrid bermudagrass (Cynodon dactylon $\times C$. transvaalensis 'Tifdwarf') under drought stress (Du et al., 2012) and in both hybrid bermudagrass and kentucky bluegrass 


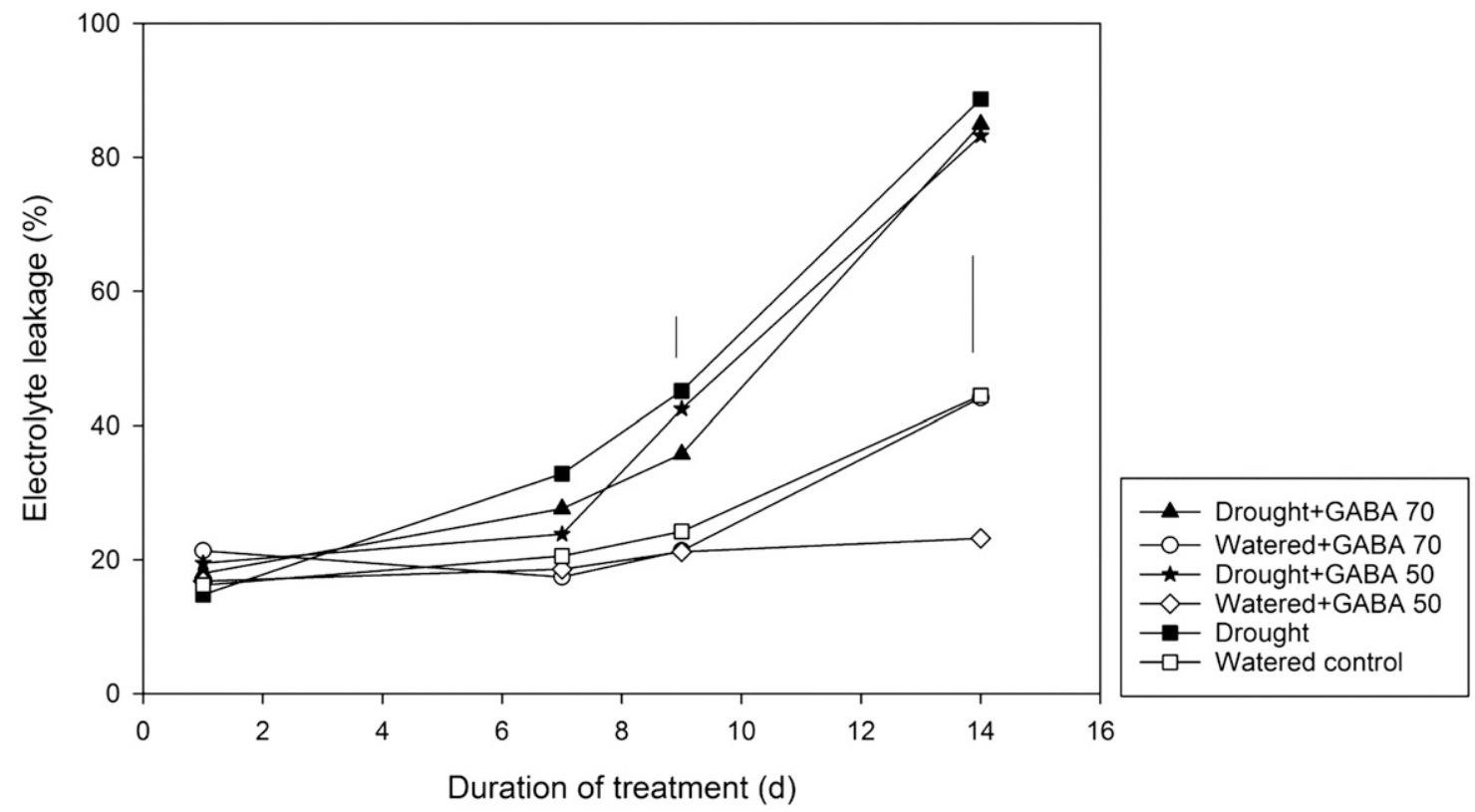

Fig. 6. Electrolyte leakage of perennial ryegrass 'CSI' treated with $\gamma$-aminobutyric acid (GABA) at 50 or 70 mm under well-watered and drought conditions. Vertical least significant difference (LSD) bars represent least significant difference values $(P \leq 0.05)$ for treatment comparison at a given day of treatment.

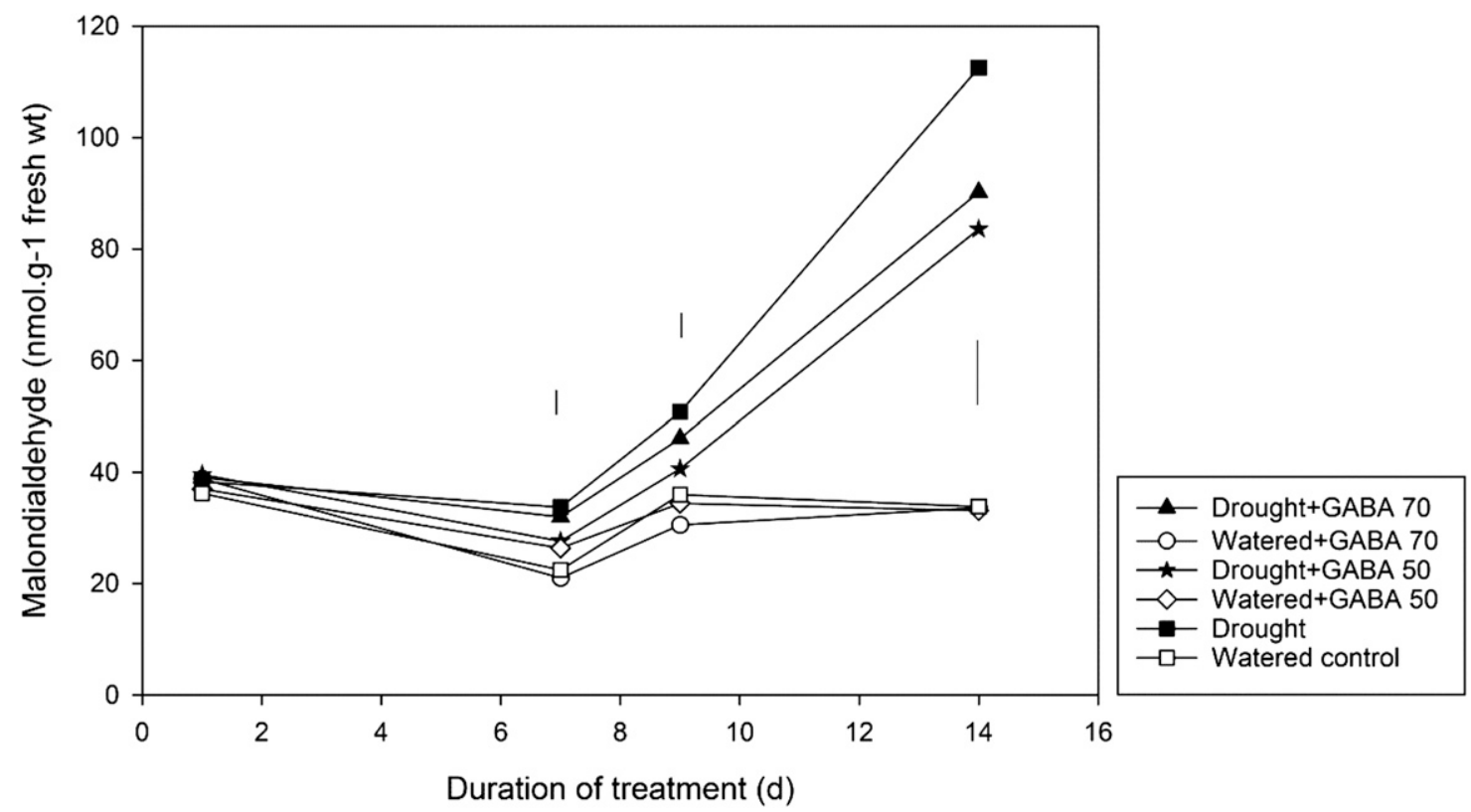

Fig. 7. Malondialdehyde content of perennial ryegrass 'CSI' leaves treated with $\gamma$-aminobutyric acid (GABA) at 50 or 70 mm under well-watered and drought conditions. Vertical least significant difference (LSD) bars represent least significant difference values $(P \leq 0.05)$ for treatment comparison at a given day of treatment.

under heat stress (Du et al., 2011) compared with controls. This suggests that GABA could play important roles in turfgrass adaptation to heat and drought stress. There is an apparent effect of GABA on turgor under drought stress with no direct explanation for this effect in this study. Further investigation could reveal the mechanism of improved leaf water status in GABA-treated perennial ryegrass under drought stress and whether it may be associated with water maintenance methods such as by osmotic adjustment.

Maintenance of leaf turgidity under drought is an important physiological adaptation and leaf wilt ratings are an indication of the severity of drought stress. Leaf wilting symptoms in turfgrasses include leaf fold, leaf roll, and blue-gray discoloration, which can be visually rated as a basis of drought tolerance (Jiang and Carrow, 2005). We observed less wilt in GABAtreated (both 50 and $70 \mathrm{~mm}$ ) perennial ryegrass under drought than non-treated plants. TQ is often used to measure overall turf performance and is a rating that gives an estimation of canopy color, uniformity, and density (Beard, 2001). The better TQ in GABA-treated perennial ryegrass could be attributed to the maintenance of higher RWC under drought stress. Further investigation of how GABA may relate to hormone responses 

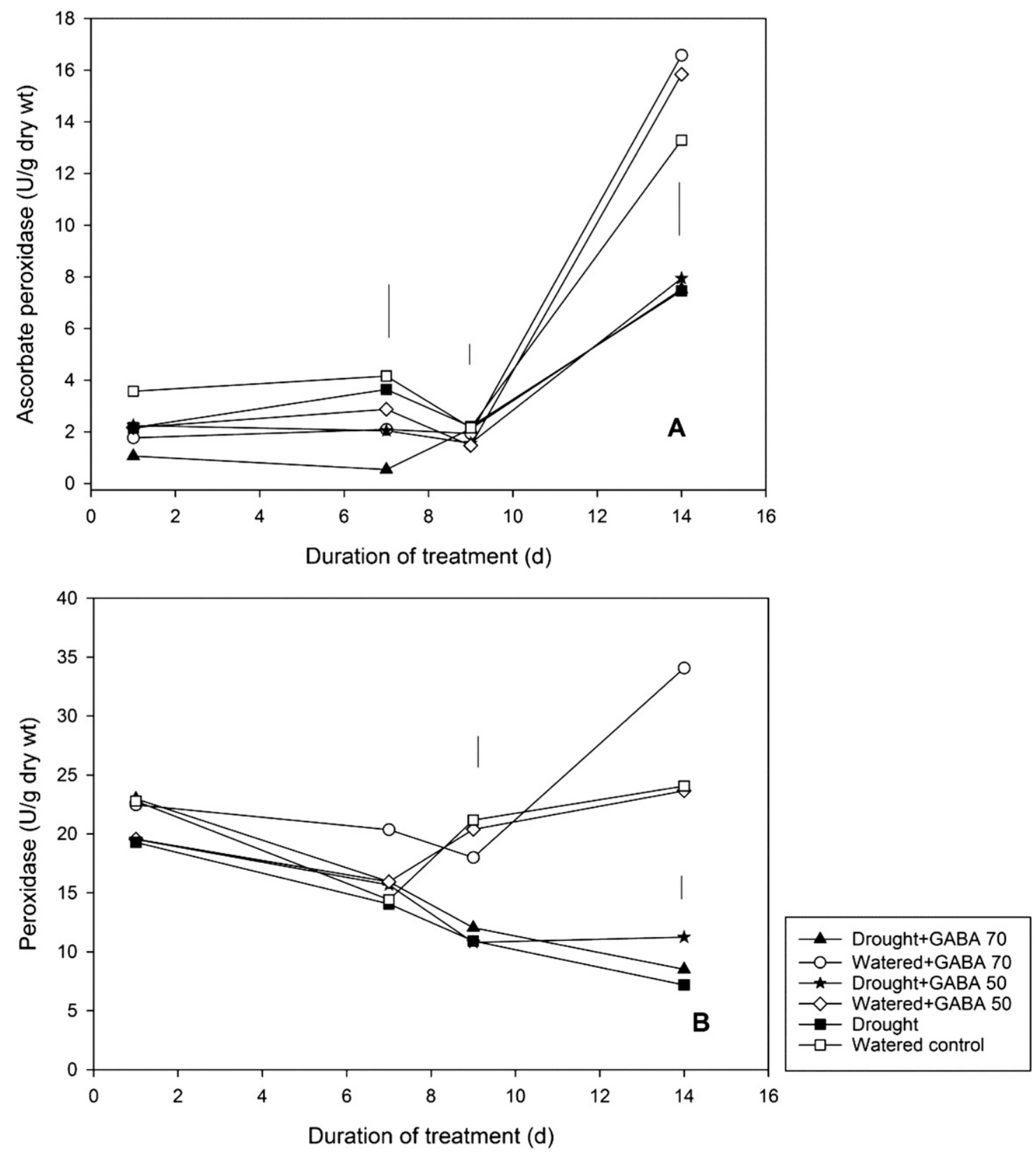

Fig. 8. (A) Ascorbate peroxidase and (B) peroxidase activity of perennial ryegrass 'CSI' leaves treated with $\gamma$-aminobutyric acid (GABA) at 50 or 70 mM under wellwatered and drought conditions. Vertical least significant difference (LSD) bars represent least significant difference values $(P \leq 0.05)$ for treatment comparison at a given day of treatment. Note the $y$-axis scaling differences for ease of comparison among treatments.

in perennial ryegrass may provide additional understanding of the maintenance TQ resulting from GABA under drought stress.

A major aspect of TQ maintenance in turfgrasses is the ability to delay leaf senescence, which can be achieved by maintenance of CK levels (Liu and Huang, 2002; Merewitz et al., 2011). Both ethylene and CK, two hormones working antagonistically during senescence, have been found to be involved in GABA metabolism and regulation under abiotic stress (Ansari et al., 2005; Shi et al., 2010). GABA has been found to accumulate to a much greater extent in transgenic creeping bentgrass with elevated CK compared with those with lower $\mathrm{CK}$ under drought stress implying that $\mathrm{CK}$ signaling may alter the flux through a GABA shunt pathway (Merewitz et al.,
2012). Similarly, many GABA-related genes were alternately regulated by the application of 6-benzyl adenine to arabidopsis seedlings grown in $10 \mathrm{~mm}$ GABA (Roberts, 2007). This suggests that CK could play a major role in regulating GABA metabolism. Ansari et al. (2005) found increased GABA transaminase (GABA-T) activity during rice leaf senescence and suggested that GABA-T could restrict the levels of reactive oxygen intermediates during leaf senescence. These studies suggest that GABA could mediate CK signaling to play a role in delaying senescence leading to improved RWC and TQ. Further study is required to elucidate the role of how hormones and GABA metabolism may be related in perennial grass species during abiotic stresses and accumulation under drought. 
Canopy temperature measurements have been widely used in recent years to study the drought response of various crops (Blum et al., 1982; Hatfield et al., 1987). This approach is based on the close, inverse relationship between leaf temperature and transpirational cooling (Jackson et al., 1981). Under drought stress conditions, soil moisture becomes depleted, resulting in reduced leaf-water potential, stomatal conductance, and transpirational cooling, which leads to elevated canopy temperature (Gates, 1964). Plants that are able to maintain a greater CTD (lower canopy temperature) during abiotic stress are generally more stress tolerant (Balota et al., 2007). We found significantly lower canopy temperatures in perennial ryegrass treated with GABA (both 50 and $70 \mathrm{~mm}$ ) across the drought stress duration. The lower canopy temperature observed in perennial ryegrasss treated with GABA could be associated with the maintenance of higher RWC, but the specific mechanism relating these two factors is not yet understood.

The maintenance of cell membrane integrity and stability under water stress conditions is a major component of drought tolerance in plants (Bajji et al., 2001). The deterioration of cell membrane stability could be a result of lipid peroxidation of membranes caused by active oxygen species (Dhindsa et al., 1981) and other cellular changes. The degree of cell membrane injury during water stress could be estimated though the measurement of EL from cells or tissues (Blum and Ebercon, 1981). Perennial ryegrass sprayed with GABA at $70 \mathrm{~mm}$ significantly reduced EL in perennial ryegrass at $9 \mathrm{~d}$ of drought. Smirnoff and Cumbes (1989) reported that GABA possesses in vitro hydroxyl radical scavenging activity exceeding that of proline and glycine betaine. Fait et al. (2005) showed a relationship between reactive oxygen species accumulation and GABA shunt metabolism in arabidopsis mutants of SSA dehydrogenase gene suggesting a role of GABA metabolism in maintaining cell membrane stability. It could be possible that one function of GABA may have protected the cell membranes of perennial ryegrass by antioxidative mechanisms resulting in reduced EL. Further work is needed to confirm this possible role of GABA in vivo. However, the results of EL and of the MDA discussed below suggest that GABA application could alleviate drought stress damage in perennial ryegrass by maintenance of better cell membrane stability.

Lipid peroxidation leads to oxidation of phospholipids, inactivation of membrane enzymes, and deterioration of cell membranes (DaCosta and Huang, 2007; Halliwell and Gutteridge, 1989). MDA content is often used as an indicator of the extent of lipid peroxidation and free radical damage to cell membranes under stress (Smirnoff, 1993). The maintenance of low levels of MDA has been associated with better drought tolerance (Sairam et al., 1998). The role of GABA in reducing the levels of active oxygen species and lipid peroxidation through an enhanced antioxidant system was not evident in the present study. It could be possible that GABA itself could be involved in scavenging the free radicals to protect the membranes because it did not activate the antioxidant enzymes. Further study is needed to determine the role of GABA in antioxidant response regulation and reactive oxygen scavenging under abiotic stress including drought.

Well-watered perennial ryegrass maintained higher antioxidant activity than drought-stressed plants throughout the study period. These results are in accordance with previous studies conducted on perennial turf species in which a reduction in APX and POD activity was observed under drought compared with watered control (Da Costa and Huang, 2007; Xu et al., 2011). POD activity was higher in $50 \mathrm{~mm}$ GABA-treated plants at $14 \mathrm{~d}$ drought. This could be related to less EL and MDA found in GABA-treated plants; however, here we did not see this consistently across sampling dates. Higher POD activity has been reported to correlate with relative drought tolerance of crop plants (Gillham and Dodge, 1987). Additional investigation regarding GABA treatment in turfgrasses is warranted to determine a possible alternate role of GABA in reducing lipid peroxidation and active oxygen scavenging.

In summary, the results from this study demonstrate that exogenous application of GABA was effective in mitigating physiological response of drought stress damage and the effects were more pronounced at the application rate of $50 \mathrm{~mm}$ than $70 \mathrm{~mm}$. GABA-treated perennial ryegrass under well-watered condition maintained higher TQ and lower EL. GABA-treated perennial ryegrass under drought maintained higher RWC, TQ, and POD activity and lower wilt, EL, and lipid peroxidation than untreated plants. GABA plays an important role in plant development and metabolism and response to stress. Further study is required to determine the function of GABA in signaling pathways and physiological responses to abiotic stress.

\section{Literature Cited}

Ansari, M.I., R.H. Lee, and S.-C.G. Chen. 2005. A novel senescence associated gene encoding $\gamma$-aminobutyric acid (GABA): Pyruvate transaminase is upregulated during rice leaf senescence. Physiol. Plant. 123:1-8.

Bajji, M., J.M. Kinet, and S. Lutts. 2001. The use of the EL method for assessing cell membrane stability as a water stress tolerance test in durum wheat. Plant Growth Regulat. 36:61-70.

Balota, M., W.A. Payne, S.R. Evett, and M.D. Lazar. 2007. Canopy temperature depression sampling to assess grain yield and genotypic differentiation in winter wheat. Crop Sci. 47:1518-1529.

Barbosa, J.M., N.K. Singh, J.H. Cherry, and R.D. Locy. 2010. Nitrate uptake and utilization is modulated by exogenous gamma-aminobutyric acid in Arabidopsis thaliana seedlings. Plant Physiol. Biochem. 48:443-450.

Barrs, H.D. and P.E. Weatherley. 1962. A re-examination of the relative turgidity techniques for estimating water deficits in leaves. Austral. J. Biol. Sci. 15:413-428.

Beard, J.B. 2001. Turf management for golf courses. 2nd Ed. Ann Arbor Press, Chelsea, MI.

Blum, A. and A. Ebercon. 1981. Cell membrane stability as a measure of drought and heat tolerance in wheat. Crop Sci. 21:43-47.

Blum, A., J. Mayer, and G. Gozlan. 1982. Infrared thermal sensing of plant canopies as a screening technique for dehydration avoidance in wheat. Field Crops Res. 5:137-146.

Bouche, N. and H. Fromm. 2004. GABA in plants: Just a metabolite? Trends Plant Sci. 9:110-115.

Bown, A.W. and B.J. Shelp. 1997. The metabolism and functions of $\gamma$-aminobutyric acid. Plant Physiol. 115:1-5.

Chai, Q., F. Jin, E. Merewitz, and B. Huang. 2010. Growth and physiological traits associated with drought survival and postdrought recovery in perennial turfgrass species. J. Amer. Soc. Hort. Sci. 135:125-133.

Chance, B. and A.C. Maehly. 1955. Assay of CAT and POD. Methods Enzymol. 2:764-775.

DaCosta, M. and B. Huang. 2006. Deficit irrigation effects on water use characteristics of bentgrass species. Crop Sci. 46:1779-1786.

DaCosta, M. and B. Huang. 2007. Changes in antioxidant enzyme activities and lipid peroxidation for bentgrass species in responses to drought stress. J. Amer. Soc. Hort. Sci. 132:319-326.

Dhindsa, R.S., P.P. Dhindsa, and T.A. Thorpe. 1981. Leaf senescence: Correlation with increased levels of membrane permeability and 
lipid peroxidation, and decreased levels of SOD and CAT. J. Expt. Bot. 32:93-101.

Du, H., Z. Wang, W. Yu, and B. Huang. 2012. Metabolic responses of hybrid bermudagrass to short-term and long-term drought stress. J. Amer. Soc. Hort. Sci. 137:411-420.

Du, H., Z. Wang, W. Yu, Y. Liu, and B. Huang. 2011. Differential metabolic responses of perennial grass Cynodon transvaalensis $\times$ Cynodon dactylon (C4) and Poa pratensis (C3) to heat stress. Physiol. Plant. 141:251-264.

Fait, A., A. Yellin, and H. Fromm. 2005. GABA shunt deficiencies and accumulation of reactive oxygen intermediates: Insight from $\mathrm{Arabi}$ dopsis mutants. FEBS Lett. 579:415-420.

Gates, D.M. 1964. Leaf temperature and transpiration. Agron. J. 56: $273-277$.

Giannopolitis, C.N. and S.K. Ries. 1977. SOD. I. Occurrence in higher plants. Plant Physiol. 59:309-314.

Gillham, D.J. and A.D. Dodge. 1987. Chloroplast superoxide and hydrogen peroxide scavenging systems from pea leaves: Seasonal variations. Plant Sci. 50:105-109.

Guo, P., M. Baum, S. Grando, S. Ceccarelli, G. Bai, R. Li, M.V. Korff, R.K. Varshney, A. Graner, and J. Valkoun. 2009. Differentially expressed genes between drought-tolerant and drought-sensitive barley genotypes in response to drought stress during the reproductive stage. J. Expt. Bot. 60:3531-3544.

Halliwell, B. and J.M.C. Gutteridge (eds.). 1989. Free radicals in biology and medicine. Clarendon Press, Oxford, UK.

Hare, P.D., W.A. Cress, and V.J. Staden. 1998. Dissecting the roles of osmolyte accumulation during stress. Plant Cell Environ. 21:535553.

Hatfield, J.L., J.E. Quinsenberry, and R.E. Dilbeck. 1987. Use of canopy temperature to identify water conservation in cotton germplasm. Crop Sci. 27:269-273.

Heath, R.L. and L. Packer. 1968. Photoperoxidation in isolated chloroplasts. Arch. Biochem. Biophys. 125:189-198.

Ingram, J. and D. Bartels. 1996. The molecular basis of dehydration tolerance in plants. Annu. Rev. Plant Physiol. Plant Mol. Biol. 47:377403.

Jackson, R.D., S.B. Idso, R.J. Reginato, and P.J. Pinter, Jr. 1981. Canopy temperature as a crop water stress index. Water Resour. Res. 17:1133-1138.

Jiang, Y.W. and R.N. Carrow. 2005. Assessment of narrow-band canopy spectral reflectance and turfgrass performance under drought stress. HortScience 40:242-243.

Karnok, K.J. 2000. Promises. Promises: Can biostimulants deliver? Golf Course Mgt. 68:67-71.

Kinnersley, A.M. and F.J. Turano. 2000. Gamma aminobutyric acid (GABA) and plant response to stress. Crit. Rev. Plant Sci. 19:479509.

Lancien, M. and M.R. Roberts. 2006. Regulation of Arabidopsis thaliana 14-3-3 gene expression by $\gamma$-aminobutyric acid. Plant Cell Environ. 29:1430-1436.

Liu, S. and Y. Jiang. 2010. Identification of differentially expressed genes under drought stress in perennial ryegrass. Physiol. Plant. 139:375-387.

Liu, X. and B. Huang. 2002. Cytokinin effects on creeping bentgrass response to heat stress. II. Leaf senescence and antioxidant metabolism. Crop Sci. 42:466-472.

Matin, M.A., J.H. Brown, and H. Ferguson. 1989. Leaf water potential, RWC, and diffusive resistance as screening techniques for drought resistance in barley. Agron. J. 81:100-105.
McCann, S.E. and B. Huang. 2007. Turfgrass drought stress physiology and irrigation management, p. 431-445. In: Pessarakli, M. (ed.). Handbook of turfgrass management and physiology. CRC Press, New York, NY.

Merewitz, E.B., H. Du, W. Yu, Y. Liu, T. Gianfagna, and B. Huang. 2012. Elevated cytokinin content in ipt transgenic creeping bentgrass promotes drought tolerance through regulating metabolite accumulation. J. Expt. Bot. 63:1315-1328.

Merewitz, E.B., T. Gianfagna, and B. Huang. 2011. Photosynthesis, water use, and root viability under water stress as affected by expression of SAG12-ipt controlling cytokinin synthesis in Agrostis stolonifera. J. Expt. Bot. 62:383-395.

Nakano, Y. and K. Assada. 1981. Hydrogen peroxide is scavenged by ascorbate specific POD in spinach chloroplasts. Plant Cell Physiol. 22:867-880.

Rathinasabapathi, B. 2000. Metabolic engineering for stress tolerance: Installing osmoprotectant synthesis pathways. Ann. Bot. (Lond.) 86:709-716.

Renault, H., A.E. Amrani, R. Palanivelu, E.P. Updegraff, A. Yu, J.P. Renou, D. Preuss, A. Bouchereau, and C. Deleu. 2011. GABA accumulation causes cell elongation defects and a decrease in expression of genes encoding secreted and cell wall-related proteins in Arabidopsis thaliana. Plant Cell Physiol. 52:894-908.

Roberts, M.R. 2007. Does GABA act as a signal in plants? Hints from molecular studies. Plant Signal. Behav. 5:408-409.

Sairam, R.K., P.S. Deshmukh, and D.C. Saxena. 1998. Role of antioxidant systems in wheat genotypes tolerance to water stress. Biol. Plant. 41:384-389.

Seki, M., T. Umezawa, K. Urano, and Shinozaki. 2007. Regulatory metabolic networks in drought stress responses. Curr. Opin. Plant Biol. 10:296-302.

Shelp, B.J., A.W. Bown, and M.D. McLean. 1999. Metabolism and functions of gamma-aminobutyric acid. Trends Plant Sci. 4:446-452. Shelp, B.J., G.G. Bozzo, C.P. Trobacher, G.C. Chiu, and V.S. Bajwa. 2012. Strategies and tools for studying the metabolism and function of $\gamma$-aminobutyrate in plants. I. Pathway structure. Botany 90:651-668.

Shi, S., Z. Shi, Z. Jiang, L. Qi, X. Sun, C. Li, J. Liu, W. Xiao, and S. Zhang. 2010. Effects of exogenous GABA on gene expression of Caragana intermedia under $\mathrm{NaCl}$ stress: Regulatory roles for $\mathrm{H}_{2} \mathrm{O}_{2}$ and ethylene production. Plant Cell Environ. 33:149-162.

Smirnoff, N. 1993. The role of active oxygen in the response of plants to water deficit and desiccation. New Phytol. 125:27-58.

Smirnoff, N. and Q.J. Cumbes. 1989. Hydroxyl radical scavenging activity of compatible solutes. Phytochemistry 28:1057-1060.

Taji, T., C. Oshumi, S. Iuchi, M. Seki, M. Kasuga, M. Kobayashi, Y.K. Shinozak, and K. Shinozaki. 2002. Important roles of drought and cold inducible genes for galactinol synthase in stress tolerance in Arabidopsis thaliana. Plant J. 29:417-426.

Turgeon, A.J. 2005. Turfgrass management. 7th Ed. Prentice Hall, Englewood Cliffs, NJ.

Xu, L., B. Han, and B. Huang. 2011. Antioxidant enzyme activities and gene expression patterns in leaves of kentucky bluegrass in response to drought and post-drought recovery. J. Amer. Soc. Hort. Sci. 136:247-255.

Yang, A., S. Cao, Z. Yang, Y. Cai, and Y. Zheng. 2011. $\gamma$-Aminobutyric acid treatment reduces chilling injury and activates the defense response of peach fruit. Food Chem. 129:1619-1622.

Zhang, X. and R.E. Schmidt. 2000. 'Hormone-containing products' impact on antioxidant status of tall fescue and creeping bentgrass subjected to drought. Crop Sci. 40:1344-1349. 